under thyroid treatment. I have also found benefit to follow the ase of suprarenal extract in lupus erythematosus; possibly owing to its influence upon the vasomotor centres. This condition is amenable to physicotherapeutic methods - to radium and carbonic acid snow but it is not a merely local affection, and when the lesions disappear under local treatment there is always the possibility of recurrence to be reckoned with. It is desir able, therefore, that further trial be given to any agent which holds out the promise of beneficially affecting the constitutional condition.

Unsolved Problems of Dermatology.

The influence which the thyroid, the pituitary, the thymus, and other glands exert on metabolism and growth, and so on the nutrition of the integuments and their appendages, suggests that further lnowledge of their nature and functions will help to solve some of the many perplexing problems of dermatology. . Bacteriology has accounted for not a few skin diseases, and vaccine-therapy and serum therapy have now a recognized place in dermatological therapeutics; but there is still a disconcertingly long list of skin affections of which the cause is unknown and the treatment purely empirical. May it not be that of some of these the explanation will be found in overaction or underaction of glands that form secretions at once so potent and so difficult of analysis? The facts that animals from which the hypophysis has been partially removed betray diminished power of resistance to infections, and that pituitary hyperplasia has been found associated with bacterial intoxications, may possibly prove to be charged with significance. It is conceivable that irregularity of this or of other organs of internal secretion may be the direct cause of certain obscure skin diseases, and that in others it may induce the predisposing condition which is the opportunity of bacterial or other pathological influences. Thus, too may possibly be explained the tendency of so many skin affections to recur after the lesions have disappeared under empirical treatment.

I will not pursue these speculations, tempting as they are. But I venture to think that the results yielded by organotherapy in a considerable number of skin affections are sufficient to warrant a more extensive use of this method of treatment in dermatology. It was by the experimental use of thyroid extract, for example, in such affections that we acquired the knowledge that now enables us in some measure to select the cases suitable for its exhibition, and only by the further use of this and other preparations in the same spirit, guided largely by the principle of analogy, will our knowledge be extended. That animal extracts must be employed with circumspection need not be said; but their effects are now tolerably well understood, and those who are practised in their use will be at no loss to recognize the conditions in which they are contraindicated.

1 BRtTISH MEDICAL JoURNAL, October 28th, 1893. 2 Albert von Haller, Element. Physiologiae, 1776. ${ }^{3}$ Johannes Müller, Lehrbuch der Physiologie, 1844. A. A. Berthold, Arch. f. Anat. u. Physiol., Artur Bied, Internal Secretory Organs (trauslation by 1855. 7 Brown-Seaniard C. R. Soc. de Biol., Paris, 1869. B BrownSéquard, ibid., 1856, xliii, xliv; 1857, xlv. "9 Brown-Séquard, ibid., 1889. 10 Sir William Gull, Trans. Clin. Soc. of Lond., vol. vii. " 11 Sir Felix Semon, Trans. Clin. Soc. of Lond., vol. xiv ; Lancet, 1883, vol. ii, 1 952. ${ }^{12}$ Professor G. R. Murray, Diseases of the Thyroid Gland, 1900. 13 E. Gley, Arch.de Physiol., 1892; Gaz. de Paris. 1892, No. 43. 14 Pierro Marie, Progres med., 1889. -15 Professor E. H. Starling, Lancet, 1905, vol.ii; p. 340. in Swale Vincent, Internal secretions and the Ductless Gur la physio-pat hopoldInternal Secretions, vol. i, $1911.19 \mathrm{H}$. W. Stelwagon, Diseases of the Skin. 20 Marbé, These de Bucarest, 1907. 21 Eason, Scot. Med. and Surg. Journ., May, 1908. 22 Moussous, Arch. de méd. des enfants, 1908 ,
p. 180. ${ }^{29}$ Arthur T. Davies, Trans. Hunterian Soc. 1901-2, p. 51. 24 J. Darier Précis de dermatologie, Paris 1909. 25 C. J White Jourm, Cut. Dis., A pril, 1912. 26 Sir A. Pearce Gould, British MEDICAL JOURNAL N2

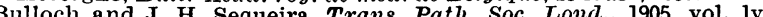
Bo 189 Profes. Sequeira, Trans. Path. Soc. Lond., 1912, 81. 1vi. . 32 W. Arbuthnot Lane, Proc. Roy. Soc. of Med., vol. vi, No. 5 (Supplement). ${ }^{33}$ Halvey Cushing, The Pituitary Body and its Disorders, ance au cours des maladies aigu ébriles du jeune age, Paris, 1907.

THE late Surgeon-General Sir Colvin Colvin-Smith Honorary Surgeon to Queen Victoria, King Edward, and King George, an Indian Mutiny veteran, left estate valued at $£ 10,708$.

\section{A Ilenture}

SOME POINTS IN THE EARLY IIAGNOSIS OF CANCER OF THE STOMACH.

Delivered at the Cancer Hospital, Brompton,

\author{
BY
}

THOMAS J. HORDER, F.R.C.P., PHYSICIAN TO THE hospital AND ASSISTANT PHYGICIAN TO ST.
BARTHOLOMEW's HOSPITAL.

IT may possibly seem to some that as my contribution to this course of lectures I have chosen to speak on an un attractive subject. "What is the good," it may be said, "when you have diagnosed cancer of the stomach? You have diagnosed an incurable disease." There are three important considerations, however, a proper appreciation of which shows the subject to be one of great consequence.

1. The incidence of the disease is high. Cancer of the stomach is a very common disease, and it is becoming more common still. Half of all cancers originate in the stomach, and in men a larger proportion even than this Whether a disease is, in its ultimate issues, incurable or not, if it is a common ailment and if it entails much suffering, it is essential that we should study it minutely and be able to reeognize it at its earliest inception.

2. The question of curability is probably in large degree a matter of early diagnosis. This consideration not only holds good to-day, whien the radical treatment of all cancers is by their surgical removal, but will no doubt hold good if and when the treatment of cancer proceeds along other than surgical lines.

Whatever chemical, physical, or biological principles govern the future treatment of cancer, it will be as im. portant to begin the treatment at the earliest possible moment as it is now important to subject the patient at the earliest moment to a surgical operation.

3. The differential diagnosis between cancer of the stomach and some other important, but less serious, maladies is often extremely difficult. The thorough in vestigation of a case of suspected cancer of the stomach provides the best possible exercise of the clinician's powers, because of the large number and the great variety of observations that must be passed in review.

I do not intend to deal to-day with purely pathological points, such as the morbid anatomy or the histology of the disease, nor shall I treat of the help in diagnosis derived from chemical investigations made upon the stomach contents after giving a test meal. I shall confine myself to the purely clinical aspects of the disease-to the sym. ptoms and signs that can be made out without the aid of special apparatus.

Briefly put, the problem is usually as follows: A man, about 40 years of age, consults us on account of dyspepsia. What are the conditions of his illness which lead us to suspect, and eventually to diagnose, gastric carcinoma?

I. History of the Present Condition.

In the history there is one very material point that quite often emerges: it is that the dyspepsia has arisen, as it were, in the midst of health. The man is not, as a rule, a chronic dyspeptic. This is rather a striking fact. There seems no doubt at all in many situations as to the predisposing effect of chronic irritation in causing cancer; but chronic gastritis does not seem to lead to new growth in the stomach. Certainly, for one case in which this sequence is observed there are a dozen in which it is absent. The rule is that patients developing gastric carcinoma have, until the beginning of the disease, enjoyed good digestion. The exception that proves the rule is the passing of a chronic gastric ulcer into carcinoma, but this, though definite enough at times, is not at all a common event. $\Lambda$ close analogy exists between this fact in the history of cancer of the stomach and a fact so often seen in the study of intestinal cancer-the difficulty with the bowels complained of by patients with this disease is very frequently their first experience of constipation. Chronic constipation does not lead to cancer, despite the theorists 
who lay 80 much stress upon " intestinal stasis" as a cause of malignant disease. To summarize this point: as we should be very suspicious of constipation arising in a patient of 60 whose bowels have moved "like clockwork" until recently, so we should strongly suspect the state of affair's leading to dyspepsia of gastric type in a man of 40 who has formerly had no indigestion.

\section{Syмptons.}

1. Anorexia.-This is an extremely common symptom, too little emphasized by the textbooks. For a long time it may be the only symptom of actual gastric origin; it may be quite unassociated with pain or vomiting. Its degree may be very marked, amounting to a positive loathing of food rather than a merely passive lack of desire for food. I recently saw a patient who said that to hear the rattle of the tray as the servant brought the meal upstairs, before the smell of the food was apparent-and the smell often causes distress-created a most unpleasant feeling of loathing. This anorexia, with the loss of flesh and strength accompanying it, is itself enough to raise suspicion of cancer of the stomach if no other cause is found. The anorexia may be for all kinds of food; at times it is for meat only. It contrasts with the state of the appetite in most cases of simple ulcer; lere the appetite is seldom lost, and is often excessive or capricious.

2. Flatulence and Heartburn.-Symptoms common to various stomach disorders, and to some that are trivial in their nature. They help little in the diagnosis of the case. There is, however, one point worth mentioning-that the feeling of distension, in the case of cancer, is but little relieved by careful choice of food. Removal of sweet stuff, and perhaps of all carbohydrates, from the diet, usually serves to diminish, it way be completely to abolish, the gastric distension present in ulcer or dilatation. This is rarely seen in carcinoma.

3. Pain is a very variable feature, perhaps the most variable of all. Occasionally it is quite absent, even thoughout the whole illness; it is sometimes a matter for surprise to see a patient with a large gastric tumour and extreme wasting quite free from pain. Unfortunately the ccntrary is the rule; cancer of the stomach is usually a very painful malady. The character of the pain differs from that of chronic simple ulcer; it is more constant, though it rarely rises to those severe heights of extreme and acute suffering scen in the hyperchlorhydria of ulcer. It is generally present as a persistent intractable achethe worst sort of stomach-ache in fact. The pain more often involves the back in cancer than in simple ulcer and the radiation of the pain commonly suggests widespread gastric adhesion. "Hunger pain" is uncommon, food seldom giving complete relief, as is often the case in ulcer.

4. Vomiting, again, is a variable symptom, but it is more constantly present than in ulcer. When it occurs it less often brings relief of pain than in simple ulcer. And careful dieting less often checks it.

5. Haematemesis. - A frank bleeding - that is to say, the vomiting of a good quantity of fresh or recently clotted blood-is distinctly uncommon in cancer of the stomach. When it occurs it is often a terminal event, and is due to the ulceration of quite a large vessel, such as the splenic artery or the pancreatico-duodenal artery, the vessel having been caught up into the base of the malignant ulcer. A patient who faints, or who is left blanched, as the result of a severe haematemesis-or of a severe melaena, for the same argument holds good-is much more likely to be suffering from a simple ulcer than from a carcinoma. This point in differential diagnosis is not altered by the fact that the patient's age is over 40 ; chronic ulcer is not uncommon round about the age of 50 , and occurs even later than this. It is not a single large haemorrhage but steady slight oozing that characterizes cancer. This oozing shows itself, by careful inspection of the vomit, in two ways: (a) By the so-called "coffee grouiss," a sediment of dark brown material, sometimes only distinguishable from the dark residue of gastric stasis by spectroscopic examination; (b) by small black specks or shreds which are in reality small clots altered by the action of acids in the stomach. The identification of one or of both of these forms of blood is of the utmost importance. Single findings are not; of course, of nearly such significance as repeated findings.
6. Loss of flesh.-Despite the fact that some patien's with gastric cancer lose no weight, or actually gain weight under preliminary treatment, the fact remains that the great majority progressively lose weight, and this in spite of treatment. In almost every wasting disease the patient may come under observation in a condition when the general nutrition is below that degree necessarily imposed by the extent of his lesion. No conclusion, therefore, should be deduced in this respect until he has been at rest and under treatment for about fourteen days. If, at tho end of this time and despite treatment, the weight still falls, a case of stomach clisease is almost certain to bo either cancer or extreme pyloric stenosis, or, of course, a combination of both of these-that is, the observer is dealing either with a condition of relative starvation from mechanical obstruction at the pylorus or with progressive malignant disease. And it is not very difficult to decide between these two states. In connexion with chronic diseases of the stomach, therefore, careful periodic weighings are of the utmost importance.

7. Loss of Strength.-Asthenia is significant, but not very helpful in diagnosis, unless associated with definite evidence of stomach disease.

\section{Physical Signs.}

1. Local Signs-that is, signs elicited on examination of the abdomen and adjacent parts. These signs aro found almost entirely by inspection and palpation.

(a) Inspection of the abdomen is of great importance, and is too often slurred over. For efficient observations a good light is essential, and the position of the observer should for preference be at the head and at the foot of the bed rather than at the side. In this way any asymmetry, however slight, or anything unusual in the curves of the abdomen, may be quickly detected. The effects of respiration upon the lines of the abdoncen are carefully watched. It may be advisable to inspect the abdomen again after inflation of the stomach by gas. It is convenient to remember that the two common situations of gastric cancer are (1) the region of the pylorus and (2) the region of the lesser curvature and body of the organ. (Growth at the cardiac oritice and diffuse infiltration of the whole organ are types of cancer of much less frequent occurrence.) These two common forms present two different pictures: (1) Pyloric cancer leads to dilatation of the stomach-it may be great dilatation-with (at some time or other) a small tumour in the right hypochondrium. Here the signs of dilatation are seen, and usuaily. of gastroptosis also. (2) Concer of the body of the stomach leads usually to early fixation of the organ in a more $\mathrm{cr}$ less normal position, with (at some time or other) a tumour in the epigastrium. In (1) there is apt to be a depressed epigastrium and a full hypogastrium; in (2) the epigastrium is apt to be full, the hypogastrium. (relatively) depressed.

(b) Palpation of the abdomen is no less important than inspection. Here a warm hand is as much a desideratum for successful examinations as a good light was in inspection. The position of the patient is that in which the muscles are most relaxed. It is sometimes helpful to palpate the abclomen whilst the patient is in a warn bath. Palpation possibly discovers five things: (1) The position and size of the stomach if this is dilated; $(2)$ the presence of a tumour ; (3) rigidity of muscles; (4) tenderness; and (5) enlarged glands or secondary masses in other organs than the stomach. It is well to emphasize the importance of localized rigidity of muscle-a finding that is only secondary in importance to the discovery of a tumour. Constant rigidity of certain areas of the rectus abdominis, such as the upper part of the left rectus, in a case of suspected cancer on other grounds, is probably sufficient to justify operative procedure. For it must be remembered that this rigidity riay conceal a tumour, and even if this be not the case, it is important to operate on gastric cancer before the growth is so large as to yield an abdominal tumour on examination. When rigidity is definite it is well to examine under chloroform ; the absence of a tumour in these circumstances raises the question of chronic simple ulcer. In palpating for enlarged glands the region of the supraclavicular triangles must not be omitted.

2. General Signs.-These include some very important features. 
(a) Anaemia.-Blood examination yields definite differential help between cancer and simple ulcer. For if considerable haemorrhage be excluded, the presence of any degree of anaemia greatly favours cancer-or, to be more accurate, it should be said that the absence of anaemia is much against cancer. In pyloric stenosis due to simple fibrosis, as from an old healed ulcer, wasting may be extreme, and yet there may be little or no anaemia ; the condition is largely one of starvation, and in starvation the blood suffers relatively little. Whereas ofttimes a patient in whom the degree of wasting is less, but who suffers from gastric cancer, yields a red blood count and haemoglobin percentage considerably below normal. Too much importance can scarcely be attached to this point.

(b) Fever.- When fever is present in a chronic case of stomach disease, the nature of the disease is more likely to be malignant than simple ulcer. It is not, however, common-it is not nearly so common as in cancer of the large bowel.

(c) Cachexia is a late sign, and therefore one I will not dwell upon.

(d) The tongue gives very little, if any, help. Its state is very dependent upon local conditions, as of the teeth, pharynx, etc.

The data obtained as the result of all these considerations is supplemented by observations of the stomach contents rernoved after giving a test meal. It is important that more than one such observation should be undertaken. In some cases a series of $x$-ray pictures after a bismuth meal will still further assist the diagnosis. As the result of all these methods, and not as the result of any one alone, a diagnosis of cancer of the stomach should be arrived at as early as possible. In concluding, let me draw your attention to these two specimens in our museum; they both illustrate successful operations upon cases of cancer of the stomach. In the first the growth which you see was removed seven years ago; in the second, two and a half years ago. Both patients are today alive and quite well. Such results as these, albeit not common, should stimulate us to active and thorough efforts at early diagnosis of this important disease.

\section{AN INSTANCE OF LARGE URETERAL CALCULUS AND SOME OTHER CASES OF CALCULI.*}

By GEORGE WHERRY, M.C.CANTAB., F.R.C.S.Eng., LECTURER ON SURGERY, UNIVERSITY OF CAMBRITGE.

I RECORD my five cases in which calculi have been removed by operation. Four were renal or ureteral, and in one a stone was excised from the perineum. In the cases of renal and ureteral stone the $x$-ray photographs proved very helpful.

\section{CASE $\mathrm{I}$}

The first case is that of a girl, aged 16 years, from whom large calculi were removed from the pelvic portion of ithe righ large calculi were removed from the pelvic portion of ithe right to Addenbrooke Hospital under the care of Dr. Bradbury, by to Addenbrooke Hospital under the care of Dr. Bradbury, by whose kindness I was called in to consider the case. It should be noted that there was very little in this girl's condition to call attention to her real malady. She was admitted with pains in the joints and epigastric pains; : there was some swelling of the knee-joints on both sides; she had pain in the right side of her chest, aggravated by coughing, and had not felt well for a month: There was a history of pneumonia and pleurisy two years before, and frequent sore throat. The urine was acid free from albumen and sugar. She was watched during five weeks until an access of fever and abdominal pain led to further examination of the urine, in which pus and blood were found, and some crystals of oxalic acid. Digital examination by the rectum detected a hard mass on the right of the uterus; under an anaesthetic this mass was felt to be fixed, but not connected with the uterus. The $x$ rays made it almost certain that there were calculi in the ureter; $a$ clear space was to be seen around the stones inside the ring of the true pelvis. As the patient's condition was certainly growing true pelvis. As the patient's condition was certainly growing
worse it was decided to operate. Her temperature varied worse it was decided to operate. Her temperature varied
from $101.4^{\circ}$ on the day of admission to $104.2^{\circ}$ on the day of from 101.4

Operation.-Through a median incision the abdomen was opened, and then with the patient in the Trendelenburg position two large calculi were found in the pelvic portion of the ureter. The stones were fixed and could not be pushed

* Read before the Cambridge and Buntingdon Branch of the British edical Association. upwards or downwards. The ureter was clamped above; an incision was made, and the stones removed; about two ounces of purulent urine was swabbed out. The ureter was sewn up with catgut, using a harelip needle. The patient was then placed in the horizontal position and the suturing tested; so that the pressure in the ureters was tried in two positions. The clamp was removed and the abdomen closed in the usual way without the use of drainage.

In this case the calculi were so deep in the pelvis as to make it a question whether it would not be better to pursue the bolder course of operating through the peritoneum rather than by the usual extraperitoneal route. In the latter procedure the consideration of the large size of the wound, the difficulty of suturing the ureters, and the certainty that a drain would have to be used, with long delay in healing, decided me to venture on the operation above described, in spite of the very real risk of leakage of purulent urine into the peritoneal cavity. However, a good recovery was made, the temperature came down at once to normal, and except for washing out the bladder with boric lotion there was no trouble with the nursing. In textbooks the extraperitoneal method is recommended. But it is obvious that methods may be combined of operating through the peritoneal cavity and then making a drain from the pelvic basin to the exterior, directed from within ky a limited incision. There is the possibility also of pushing the stone upwards to the pelvis of the kidney or downwards to the bladder. The two narrow points where stones commonly lodge are just below the kidney and, lower down, some two inches above the bladder. In the pelvic end of the ureter stones are fortunately not so often found.

It has chanced to many surgeons, as it has chanced to me, to cut through a healthy ureter which bas become involved in a tumour, and on the ureter being carefully stitched no trouble beyond anxiety to the surgeon has resulted. But in dealing with pathological cases in which the ureter is dilated and contains urine loaded with bacilli, the risks must be serious. With regard to the technique of the operation, there is much to be said in favour of an intestinal needle instead of a harelip needle unless the tissues are very thick, but in any case catgut, not silk, should be used lest a crust should subsequently deposit on the silk. The stones removed from Case $r$ were of large size. Together they measured $2 \frac{1}{2}$ in. by 1 in. diameter, and their weight when dry was 226 grains and 91 grains $=317$ grains.

\section{CASE II.}

The next case is that of George S., aged 23, who had calculi in both kidneys. The stone in the right kidney was first in both kidneys. The stone in the right kidney was first removed. In this operation there was nothing unusual and a good recovery was made, but on the left side there was a great collection of pus, and as the stone in the ureter could not be reached from the loin, a large drainage tube was put into the abscess cavity, and when a certain stage of recovery had been
reached and the cavity had contracted, an abdominal intrareached and the cavity had contracted, an abdominal intraperitoneal operation was planned and the stone pushed into the
kidney. This done, the incision in the loin was enlarged along the drain tube, and the stone extracted with a scoop. The patient made a good recovery, and wrote to the hospital on May 23 rd to state that he was well and about to start work.

CASE III.

This was a chauffeur, aged 28 , who had continued his work until his admission to hospital under the care of Dr. Bradbury. He had pain in the left loin, which had begun only about five weeks previously. He had passed blood on one occasion only; it was after taking urotropin. About a year previously he had an attack of appendicitis, but recovered without operation: thirteen years ago he had had a vesical calculus removed by lithotrity. On admission there was tenderness over the left renal area; the urine was loaded with pus, but showed no blood orat area, the urine was loaded with pus, but showed no blood or casts, and a skiagram demonstrated calculi in the left kidney. At the operation were removed masses of phosphatic débris too friable to hold together in the scoop, and the whole kidney was distended with purulent urine and in a state of phosphatic pyelonephritis. Thorough douching was used to clear the
cavities of crusts as well as possible, and a large drainage tube cavities of

The patient did well, but there was pus in the urine for some weeks, and an $x$-ray photograph taken since the operation still shows the shadows of phosphates. His general condition is excellent.

Case IV.

This was a countrywoman, who, though stout, looked pale and feeble; she had been ill and in great pain for many months past, and had constantly passed large quantities of pus with the sought relief at the hospital. With all her stoutness it was 